\title{
Facial application of high-concentration carbon dioxide prevents epidermal impairment associated with environmental changes
}

This article was published in the following Dove Press journal:

Clinical, Cosmetic and Investigational Dermatology

\section{Katsuyuki Yuki \\ Sawako Kawano \\ Shinobu Mori \\ Takatoshi Murase}

Biological Science Laboratories, Kao Corporation, Ichikai-machi, Haga-gun, Tochigi, Japan
Correspondence: Takatoshi Murase 2606 Akabane, Ichikai-machi, Haga-gun,

Tochigi 321-3497, Japan

Tel +8I 285687000

Fax $+8 I 285687360$

Email murase.takatoshi@kao.co.jp
Purpose: The transdermal application of carbon dioxide $\left(\mathrm{CO}_{2}\right)$ gas dissolved in a solution and bathing in carbonated springs have been known to improve circulatory disorders. We aimed to elucidate and profile the effects of $\mathrm{CO}_{2}$ application on local skin function.

Patients and methods: A liquid formulation that included high-concentration $\mathrm{CO}_{2}$ or a control formulation was applied to the face of healthy men for 8 weeks. Quantitative analysis was performed during the dry winter months.

Results: At the site where the control formulation was applied, transepidermal water loss (TEWL) increased while the moisturizing function (conductance) of facial skin decreased during the study period. However, at the $\mathrm{CO}_{2}$-treated site, increases in TEWL and decreases in conductance were significantly suppressed. In addition, the deterioration in scaliness and wrinkles parameters were suppressed by $\geq 40 \%$ at the $\mathrm{CO}_{2}$-treated site. There were no significant differences in skin surface $\mathrm{pH}$ or color properties between the control and test sites.

Conclusion: This study suggests that the continuous application of a high-concentration $\mathrm{CO}_{2}$ formulation can affect skin physiology and has the potential to suppress reductions in the barrier and moisturizing functions of the stratum corneum accompanied by desquamation, which occurs during the winter.

Keywords: transepidermal water loss, stratum corneum, barrier, desquamation

\section{Introduction}

The skin is the largest organ and covers the entire body. The epidermis and its outermost layer, known as the stratum corneum, play a critical role in protecting the body from various external factors, such as dry air, ultraviolet light, and chemical substances, via a barrier function that prevents water loss from the body surface and by retaining water within the skin. ${ }^{1}$ Previous studies have revealed that proteins related to skin structure and cell adhesion, skin surface lipids, and intercellular lipid components in the stratum corneum such as ceramides, free fatty acids, and cholesterol, and natural moisturizing factor (NMF), which is composed of amino acids and organic acids, are critical in maintaining the physiological functions of the stratum corneum. ${ }^{2,3}$ As factors that are liable to disrupt skin homeostasis, changes in the external environment, such as ultraviolet light and climate, and changes in health status can cause changes in the amount and composition of the abovementioned functional molecules in the stratum corneum, leading to reduced skin barrier and moisturizing function. ${ }^{4,5}$ In addition, disruptions in the normal turnover of the epidermis and abnormalities in the keratinization process and structural proteins lead to changes in the skin's external appearance, such 
as scaling and cracking, as well as the onset of xeroderma and ichthyosis. ${ }^{3}$ Refractory skin disorders that involve chronic inflammation and allergic reactions lead to marked reductions in quality of life and worse esthetic appearance. ${ }^{6,7}$ Therefore, if the mechanism that regulates the structure and function of skin and the factors that affect this mechanism can be controlled, skin homeostasis may be maintained.

Carbon dioxide $\left(\mathrm{CO}_{2}\right)$ is one of the biogases produced within the body and plays a role in the body's physiology. This study was prompted by the fact that naturally occurring $\mathrm{CO}_{2}$ springs have long been used to improve health conditions and have a wide variety of applications. $\mathrm{CO}_{2}$ bathing and transdermal administration of $\mathrm{CO}_{2}$ are reported to be effective in improving circulatory and immunological disorders, such as hypertension, artery occlusion, intermittent claudication, and Raynaud's syndrome. ${ }^{8-15} \mathrm{CO}_{2}$-induced changes in hemodynamics, microcirculation, vasomotion, and thermoregulation in human skin (healthy or disordered) have been confirmed using near-infrared spectroscopy, magnetic resonance imaging, blood flow meters, and thermography. An acute vasodilator action of $\mathrm{CO}_{2}$ application and an increase in the peripheral blood flow of rats were demonstrated using in vivo imaging with intravital microscopy. ${ }^{16} \mathrm{~A}$ previous report regarding a molecular mechanism showed that the $\mathrm{CO}_{2}-$ induced vasodilation of peripheral blood vessels is related to the activation of the nitric oxide-cyclic guanosine monophosphate signaling cascade and angiogenesis by induction of the synthesis of VEGF. ${ }^{13}$ Another important mechanism of $\mathrm{CO}_{2}$ is the Bohr effect, which seems to be responsible for acute microenvironmental changes after $\mathrm{CO}_{2}$ application, such as decreases in oxygen-hemoglobin, increases in partial pressure of oxygen, and decreases of $\mathrm{pH}$ in peripheral tissue. ${ }^{18} \mathrm{~A}$ study of the efficacy of $\mathrm{CO}_{2}$ on skin symptoms reported that a high-concentration $\mathrm{CO}_{2}$ solution is effective in promoting the healing of wounds and ulcers and is useful in suppressing erythema in artificially damaged skin. ${ }^{14}$

Although many uses of $\mathrm{CO}_{2}$ have been reported, the effect of the external application of $\mathrm{CO}_{2}$ on the surface properties and physiology of skin remains unclear. The face is a specific site, which is constantly exposed to a harsh external environment and located where any change in appearance is very noticeable. The present study aimed to identify the effect of transepidermal application of $\mathrm{CO}_{2}$ on facial skin properties. By performing quantitative analyses of skin surface profiles and functional parameters using instruments to measure and analyze these factors, we were able to ascertain the changes in the skin's appearance and function that occur during the dry winter season and characterize the effects of the long-term application of $\mathrm{CO}_{2}$ formulations on these changes.

\section{Materials and methods Subjects}

The subjects for this study were healthy Japanese men residing in Tochigi, Japan. Since the skin condition of women may be affected by menstruation, we avoided the influence of this potential confounder. We excluded individuals who had skin diseases or impaired vascular function, drank three or more cups of coffee per day, consumed supplement or medicines, had allergies, and smoked. This study received the approval of the ethics committee of the Kao Corporation. The approval number was \#641-2-150331. It was conducted according to the study protocol and in accordance with the clinical research ethical guidelines of the Kao Corporation and the ethical principles of the Declaration of Helsinki. The subjects were provided with an explanation of the conditions and methods of the study, and written consent was obtained from each of them.

\section{Test samples}

We designed the following test samples to maintain $\mathrm{CO}_{2}$ gas in the dissolved state at high concentration and to be suitable for external application to the face: thickened and water-based emulsion consisting of cosmetics-grade materials. The formulation contained water, dipropylene glycol, propanediol, and lauryl methacrylate/sodium methacrylate crosspolymer as bases, acrylates/alkyl acrylate (C10-30) crosspolymer as a thickener, and dimethicone and alkyl benzoate (C12-15) as oils. The water and oil bases were emulsified with polyethylene glycol-60, hydrogenated castor oil, and polyethylene glycol-12 dimethicone (dimethicone/vinyl dimethicone) crosspolymer as surfactants and were supplemented with potassium hydroxide, potassium phosphate, disodium ethylenediaminetetraacetic acid, phenoxyethanol, and methylparaben for buffering and preservation. The test samples were filled with $\mathrm{CO}_{2}$ gas at a saturated concentration ( $\mathrm{CO}_{2}$ concentration: $\left.\sim 1,170 \mathrm{mg} / \mathrm{L}\right)$ as a $\mathrm{CO}_{2}$ formulation, and a control formulation was made by combining the same base substances without adding $\mathrm{CO}_{2}$ gas $\left(\mathrm{CO}_{2}\right.$ concentration: $\sim 10 \mathrm{mg} / \mathrm{L})$.

\section{Study design}

This study employed a double-blind parallel-group design. The test samples were applied to the cheeks: the control formulation on one side of the face (right or left) and on the 
other side, the $\mathrm{CO}_{2}$ formulation (the two sites will hereafter be referred to as the "control site" and " $\mathrm{CO}_{2}$ site", respectively). The application was performed twice per day: in the morning after the subjects washed their faces and at night after the subjects had bathed. The application period was 8 weeks. Measurements were recorded, and analyses were performed prior to application ( 0 week) and 4 and 8 weeks after the start of the application. For 2 days prior to the measurement day, the consumption of foods and drinks containing alcohol, caffeine, and strong spices was prohibited. On the days of measurement, the subjects washed their faces and were allowed to acclimatize to an environment with a temperature of $20^{\circ} \mathrm{C} \pm 2{ }^{\circ} \mathrm{C}$ and a humidity of $40 \% \pm 5 \%$ for 20 minutes prior to skin measurements.

\section{Measurements of stratum corneum function}

Transepidermal water loss (TEWL), which is a parameter of epidermal barrier function, was measured using a Tewameter TM300® (Courage + Khazaka electronic GmbH, Cologne, Germany). Continuous measurements were taken for a period of 180 seconds, during which the sensor probe of the device was lightly applied to the application target sites. Mean values were calculated from values obtained for 30 -second periods of stable measurement. The measurements were repeated two times and the mean values were calculated. Conductance, which is a parameter of moisturizing function, was measured using a skin surface hygrometer (SKICON-200EX®; I.B.S. Co., Hamamatsu, Japan), and the mean value of five measurements was calculated.

\section{Measurements of skin surface condition}

Microscopic examination of the external appearance of the skin was performed using a dry skin microscope MC50T® (Integral Corporation, Tokyo, Japan) to obtain enlarged images of the skin surfaces. Skin surface profiles, such as micro-relief, were obtained using a Visioscan ${ }^{\circledR}$ VC 98 USB with light engineering technology (Courage + Khazaka Electronic $\mathrm{GmbH}$ ). Images of each site were obtained, and all parameters associated with microstructures on the skin surface were analyzed. Specifically, the following parameters were used: skin smoothness (SESM), roughness (SER), scaliness (SESC), and wrinkles (SEW). Smaller SESM values indicated smoother skin. Larger values of SER, SESC, and SEW indicated more roughness, scaliness, and wrinkles, respectively. Skin $\mathrm{pH}$ was measured using a skin $\mathrm{pH}$ meter (PH905; Courage+ Khazaka Electronic $\mathrm{GmbH}$ ) and skin color properties were measured using a spectrophotometer (CM2600d; Konica Minolta Japan, Inc., Tokyo, Japan). Each site was measured five times, and the mean values for the $\mathrm{pH}$ values and the color properties related to brightness $\left(\mathrm{L}^{*}\right)$, redness $\left(a^{*}\right)$, and yellowness $\left(b^{*}\right)$ were calculated.

\section{Statistical analyses}

Statistical analyses were performed using SPSS statistics (IBM Corporation, Armonk, NY, USA). The results were presented as mean and standard errors. Since the normality of all data sets was confirmed with a histogram and quantilequantile plot, the following comparison tests were conducted: the values at 0 week and at 4 and 8 weeks were assessed using Dunnett's test. Two-way repeated-measures ANOVA or the paired $t$-test was performed to analyze the differences between the two application conditions of application. Statistical significance was defined as $P<0.05$.

\section{Results}

Excluded subjects, application volume of test samples, and adverse effects during the test periods

The subjects of this study were 20 men aged 26-59 years (mean age: $40.3 \pm 2.3$ years). One of the 20 subjects consumed a vitamin supplement during the study period and was excluded from the analyses. Therefore, the data obtained from the remaining 19 subjects were used. The mean quantity of the test samples used on the subjects was $0.7 \mathrm{~g}$ of the formulation and showed no significant difference between the two applications. No adverse events occurred during the study period.

\section{$\mathrm{CO}_{2}$ application suppressed the increase in TEWL and decrease in skin hydration in the stratum corneum}

The absolute values for TEWL and conductance are shown in Table 1. A statistically significant difference in absolute conductance values for the control and $\mathrm{CO}_{2}$ sites was found at 8 weeks $(P=0.017)$. As shown in Figure $1 \mathrm{~A}$, the extent of change from the 0 -week baseline $(\triangle \mathrm{TEWL})$ in the control sites significantly increased at 4 and 8 weeks $(P=0.0005$ and $P=0.001$, respectively), whereas the increase at the $\mathrm{CO}_{2}$ sites was not statistically significant. The extent of conductance change from 0 week ( $\Delta$ Conductance) (Figure 1B) indicated that the control sites showed a significant decline at 4 and 8 weeks ( $P=0.005$ and $P=0.006$, respectively), whereas the 
$\mathrm{CO}_{2}$ sites showed no significant changes. The difference in $\Delta$ Conductance between the two sites at 8 weeks was statistically significant $(P=0.027)$ and indicated that $\mathrm{CO}_{2}$ led to a suppression of $\Delta$ Conductance of $\sim 62 \%$. Conclusively, the changes in stratum corneum function observed during the study period at the control sites were suppressed at the $\mathrm{CO}_{2}$ sites.

\section{Deterioration of scaliness and wrinkles on the skin surface was suppressed by $\mathrm{CO}_{2}$ application}

The absolute values for SESM, SER, SESC, and SEW in the skin surface profile are shown in Table 2. There were significant differences between the control and $\mathrm{CO}_{2}$ sites in terms of SESM $(P=0.023)$, SESC $(P=0.026)$, and SEW $(P=0.019)$. There was decreased exfoliation or minute wrinkles and the skin surface became smoother at the $\mathrm{CO}_{2}$ sites. $\triangle \mathrm{SESC}$ showed significant increases at the control sites $(P=0.004$ at 4 weeks and $P=0.042$ at 8 weeks) during the study period (Figure 2). In contrast, $\triangle \mathrm{SESC}$ was small at the $\mathrm{CO}_{2}$ sites.

Table I Parameters of epidermal function at each time point

\begin{tabular}{|l|l|l|l|l|}
\hline & & 0 week & 4 weeks & 8 weeks \\
\hline \multirow{3}{*}{$\mathrm{TEWL}\left(\mu \mathrm{g} / \mathrm{m}^{2} / \mathrm{h}\right)$} & Control & $27.6 \pm 1.0$ & $35.1 \pm \mathrm{I} .6$ & $34.4 \pm \mathrm{I} .4$ \\
\cline { 2 - 5 } & $\mathrm{CO}_{2}$ & $30.6 \pm 1.4$ & $34.8 \pm 1.6$ & $35.6 \pm 1.6$ \\
\hline Conductance $(\mu \mathrm{S})$ & Control & $89.6 \pm 8.7$ & $58.9 \pm 7.7$ & $59.6 \pm 6.2$ \\
\cline { 2 - 5 } & $\mathrm{CO}_{2}$ & $83.4 \pm 9.8$ & $67.0 \pm 8.8$ & $72.1 \pm 7.4^{*}$ \\
\hline
\end{tabular}

Notes: Values are mean \pm SE $(n=19) .{ }^{*} P<0.05$ vs control at 8 weeks via paired $t$-test. Conductance, water content in the stratum corneum.

Abbreviation: TEWL, transepidermal water loss.
The difference in $\triangle \mathrm{SESC}$ at 8 weeks between the two sites was statistically significant $(P=0.016)$. Deterioration of skin surface properties was suppressed by the $\mathrm{CO}_{2}$, and this effect became more pronounced with an increase in the application period.

Microscopic images of the skin surface indicated that at the control sites, scaling increased over time compared to that at 0 week, whereas at the $\mathrm{CO}_{2}$ sites, these changes were small (Figure 3).

Regarding other skin surface parameters, the absolute values for skin surface $\mathrm{pH}$ and color properties are shown in Table 2. All values for skin surface $\mathrm{pH}, \mathrm{L}^{*}, \mathrm{a}^{*}$, and $\mathrm{b}^{*}$ showed no significant changes during the study period, and no statistically significant differences were noted between the mean values of the control and $\mathrm{CO}_{2}$ sites.

\section{Discussion}

$\mathrm{CO}_{2}$ has various uses in the clinical and pharmacological fields and has been used as a traditional therapy. Drinking carbonated water is believed to promote the activity of the digestive system, and bathing in carbonated springs is considered to improve circulatory problems and disorders..$^{8-12,20}$ The present study focused on the effects of the external use of $\mathrm{CO}_{2}$ formulation on the skin function and surface properties of the face. According to previous studies investigating the action of $\mathrm{CO}_{2}$ bathing on the circulatory system, $\mathrm{CO}_{2}$ application was found to promote dermal blood circulation when in concentrations of $\geq 60 \mathrm{mg} / \mathrm{L}$. When in higher concentrations $(>60 \mathrm{mg} / \mathrm{L})$, it was found to have a therapeutic effect on diseases accompanied by circulatory disorders such as intermittent claudication, Raynaud's syn-

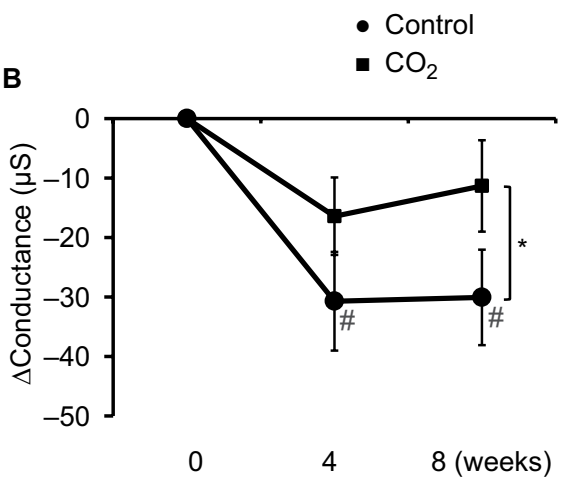

Figure I Changes in epidermal function with $\mathrm{CO}_{2}$ application.

Notes: Each parameter is shown as the amount of change $(\Delta)$ from 0 week to 4 or 8 weeks for TEWL $(\mathbf{A})$ and conductance $(\mathbf{B})$. Values are mean $\pm S E$ ( $\mathrm{n}=19)$. ${ }^{\mathrm{P}}<<0.05$, ${ }^{\#} P<0.0$ I vs 0 week by Dunnett's test. $* P<0.05$ vs control at 8 weeks via paired $t$-test. Difference in $\Delta$ Conductance between the two conditions was statistically significant via two-way repeated measures ANOVA.

Abbreviation: TEWL, transepidermal water loss. 
Table 2 Parameters of the skin surface profile and property at each time point

\begin{tabular}{|c|c|c|c|c|}
\hline & & 0 week & 4 weeks & 8 weeks \\
\hline \multirow[t]{2}{*}{ SESM } & Control & $1 \mid 4.5 \pm 5.8$ & $|2| . \mid \pm 7.7$ & $120.4 \pm 6.2$ \\
\hline & $\mathrm{CO}_{2}$ & 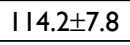 & $118.2 \pm 8.8$ & $110.6 \pm 7.4$ \\
\hline \multirow[t]{2}{*}{ SER } & Control & $2.9 \pm 0.2$ & $3.3 \pm 1.6$ & $3.3 \pm 1.4$ \\
\hline & $\mathrm{CO}_{2}$ & $3.0 \pm 0.2$ & $3.2 \pm 1.6$ & $2.9 \pm 1.6$ \\
\hline \multirow[t]{2}{*}{ SESC } & Control & $0.5 \pm 0.0$ & $0.9 \pm 1.7$ & $0.8 \pm 1.7$ \\
\hline & $\mathrm{CO}_{2}$ & $0.6 \pm 0.1$ & $0.8 \pm 2.2$ & $0.6 \pm 2.2^{*}$ \\
\hline \multirow[t]{2}{*}{ SEW } & Control & $95.6 \pm 5.2$ & $99.5 \pm 7.7$ & $104.5 \pm 6.2$ \\
\hline & $\mathrm{CO}_{2}$ & $102.9 \pm 6.5$ & $97.1 \pm 8.8$ & $94.3 \pm 7.4^{*}$ \\
\hline \multirow[t]{2}{*}{$\mathrm{pH}$} & Control & $5.9 \pm 0.1$ & $5.8 \pm 0.1$ & $6.0 \pm 0.1$ \\
\hline & $\mathrm{CO}_{2}$ & $5.8 \pm 0.1$ & $5.8 \pm 2.2$ & $6.0 \pm 0.1$ \\
\hline \multirow[t]{2}{*}{$\mathrm{L}^{*}$} & Control & $62.3 \pm 5.8$ & $62.2 \pm 0.5$ & $62.3 \pm 0.6$ \\
\hline & $\mathrm{CO}_{2}$ & $62.4 \pm 7.8$ & $62.3 \pm 0.4$ & $62.5 \pm 0.6$ \\
\hline \multirow[t]{2}{*}{$a^{*}$} & Control & $13.2 \pm 5.2$ & $13.7 \pm 0.3$ & $13.5 \pm 0.3$ \\
\hline & $\mathrm{CO}_{2}$ & $13.1 \pm 6.5$ & $13.9 \pm 0.3$ & $13.7 \pm 0.3$ \\
\hline \multirow[t]{2}{*}{$b^{*}$} & Control & $17.8 \pm 0.0$ & $17.3 \pm 0.4$ & $17.0 \pm 0.4$ \\
\hline & $\mathrm{CO}_{2}$ & $18.0 \pm 0.1$ & $17.1 \pm 0.4$ & $17.0 \pm 0.4$ \\
\hline
\end{tabular}

Notes: Values are mean $\pm S E(n=19) . * P<0.05$ vs control at 8 weeks via paired $t$-test. $L^{*}$, color property related to brightness; $a^{*}$, color property related to redness; $b^{*}$, color property related to yellowness; $\mathrm{pH}$, skin surface $\mathrm{pH}$.

Abbreviations: SER, roughness; SESC, scaliness; SESM, skin smoothness; SEW, wrinkles.

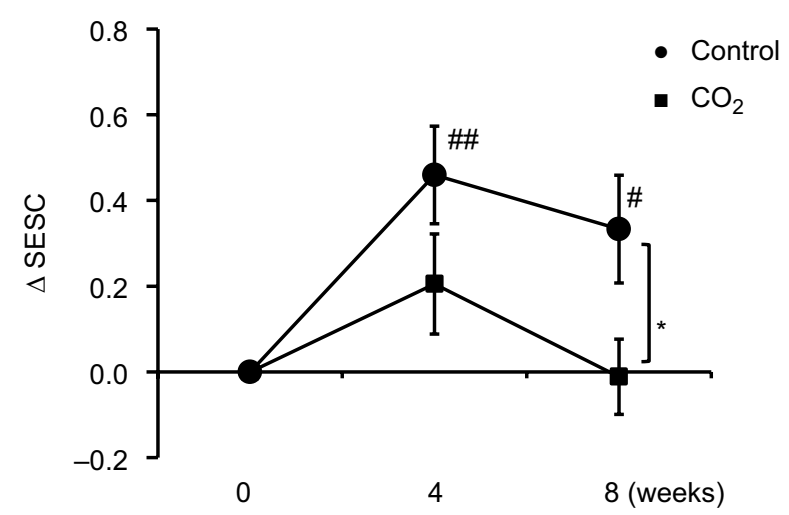

Figure 2 Changes in skin surface profile with $\mathrm{CO}_{2}$ application.

Notes: Each parameter is shown as the amount of change $(\Delta)$ from 0 week to 4 or 8 weeks for SESC. Values are mean \pm SE $(n=19) .{ }^{\# P<0.05, ~}{ }^{\# P}<0.01$ vs 0 week by Dunnett's test. ${ }^{*} P<0.05$ vs control at 8 weeks via paired $t$-test. Difference in $\triangle$ SESC between two conditions was statistically significant via two-way repeated measures ANOVA.

Abbreviation: SESC, skin scaliness.

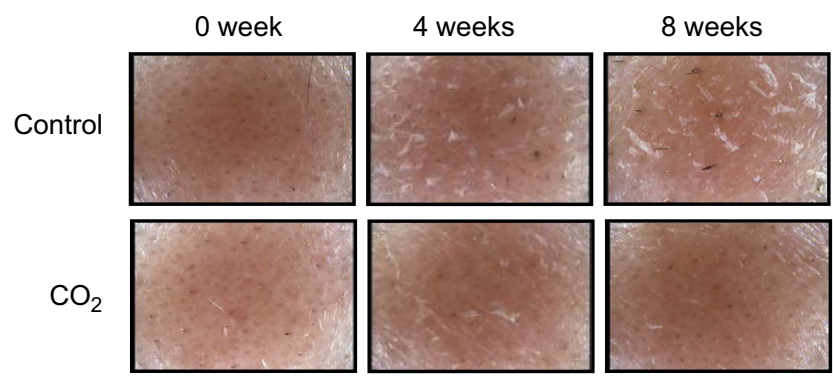

Figure 3 Changes in skin surface appearance.

Notes: Microscopic skin surface images from 0,4 , and 8 weeks obtained with the dry skin microscope are shown. The magnification rate was 30 times. The length of the long side was $6 \mathrm{~mm}$. drome, Buerger's disease, and bed sores..$^{13-16,21,22}$ Therefore, the effectiveness of $\mathrm{CO}_{2}$ on the body is thought to depend on its concentration, suggesting the need for suitable methods for the application of high-concentration $\mathrm{CO}_{2}$ on the target site. Previous studies assessed the effects of immersion in $\mathrm{CO}_{2}$-enriched solutions, $\mathrm{CO}_{2}$ bathing, or $\mathrm{CO}_{2}$ gas treatment. However, in the present study, we developed a formulation for external use with $\mathrm{CO}_{2}$ dissolved in volumes $>1,000 \mathrm{mg} / \mathrm{L}$. We confirmed that the formulation markedly enhanced dermal blood circulation (data not shown). This method allowed us to clarify the effects of the continuous application of $\mathrm{CO}_{2}$ on facial skin, which is constantly exposed to the external environment.

There are previous studies of the effectiveness of $\mathrm{CO}_{2}$ on artificially damaged skin and tissue structure. The continuous application of $\mathrm{CO}_{2}$-enriched water for 2 weeks accelerated the improvement of the barrier function decline and redness induced by treatment with sodium lauryl sulfate. ${ }^{19}$ Injection of $\mathrm{CO}_{2}$ into subcutaneous tissue improves the structure of the extracellular matrix as well as oxygen supply. ${ }^{23}$ The present study was conducted during fall and winter, when both temperature and humidity are decreased. As in previous studies, ${ }^{5,6,24,25}$ we confirmed a naturally occurring impairment of the epidermis including dryness and desquamation in the current study. The application of a high-concentration $\mathrm{CO}_{2}$ formulation for 8 weeks prevented not only decreases in conductance but also increases in TEWL and parameters related to scaliness and wrinkles evaluated using physiochemical and light engineering equipment. ${ }^{26,27}$ Surface roughness and wrinkles increase and the amount of water in the stratum corneum decreases in aging skin, and these effects are improved by the application of a moisturizer. ${ }^{27-29}$ The efficacy of the $\mathrm{CO}_{2}$ formulation on the skin's moisturizing function suggests its ability to suppress dryness-related changes in the stratum corneum and bring about improvement in the microstructures of the sulcus cutis and crista cutis. Worsening of the skin's external appearance, including cracking and scaling, is caused by environmental factors such as low temperatures and causes delayed exfoliation and excessive layering of the stratum corneum. ${ }^{3}$ The efficacy of $\mathrm{CO}_{2}$ application on the scaliness parameter suggests that $\mathrm{CO}_{2}$ possibly normalizes the balance in keratinization and the layering process, improving the appearance of desquamation. Further study is still required to confirm these actions of $\mathrm{CO}_{2}$ and to establish their relation to the smoothening effect.

Decreases in the barrier function and moisturizing function of the stratum corneum are occasionally accompanied by chronic inflammation and other microenvironmental 
changes. ${ }^{6}$ Our analyses of the skin color parameters related to the amount of hemoglobin and melanin, which are associated with inflammatory-induced erythema, pigmentation, or vascular alteration, revealed no significant changes. Therefore, this study produced no evidence that $\mathrm{CO}_{2}$ has an effect on these factors.

When considering the mechanism of action of $\mathrm{CO}_{2}$ related to its improvement of skin functions, it is necessary to consider both the indirect effects on the skin via blood circulation and the direct effects on the skin. Although a healthy circulatory system is essential for maintaining the homeostasis of peripheral tissues, few studies have investigated the relationship between skin and dermovascular functions. In recent years, Yoshida-Amano et al reported that the recovery rate from decreased skin temperature due to cold stress is positively correlated with the water content in the stratum corneum, and Nomura et al reported a negative correlation between dermovascular responsiveness to temperature changes and TEWL. ${ }^{30,31}$ It has also been reported that TEWL is high in patients with chronic venous insufficiency who experience blood stagnation. ${ }^{32}$ Therefore, it is possible that the effect of $\mathrm{CO}_{2}$ on the maintenance and improvement of skin properties observed in the present study may also have been due to some involvement of $\mathrm{CO}_{2}$ in blood circulation or vascular function.

It is also necessary to consider the direct effects of $\mathrm{CO}_{2}$ on skin tissues. $\mathrm{CO}_{2}$ is ionized in part as hydrogen carbonate in a water solution and emits protons, inducing a decrease in $\mathrm{pH}$. It is known that the skin surface $\mathrm{pH}$ is adjusted to a weakly acidic state (about $\mathrm{pH}$ 5.7), which is important for the maintenance of the skin barrier and water retention functions. ${ }^{33}$ Skin surface $\mathrm{pH}$ is correlated with both the amount of water and NMF synthesis but increases with aging. ${ }^{3}$ Thus, it has been reported that the suppression of an increase in skin surface $\mathrm{pH}$ alleviates senile xerosis. ${ }^{34-36}$ However, no significant changes in skin surface $\mathrm{pH}$ were observed in the present study, and the contribution of $\mathrm{pH}$ to the efficacy of $\mathrm{CO}_{2}$ application could not be identified. Sakai et al showed the possibility of an artificial Bohr effect as a cause of decreased $\mathrm{pH}$ and increased partial pressure of oxygen in dermal tissue after $\mathrm{CO}_{2}$ application. ${ }^{18}$ When considering this effect, we assume that the penetration of high-concentration $\mathrm{CO}_{2}$ molecules into tissues induces transient hypoxia within the tissues. In recent years, hypoxiainduced factor- $1 \alpha$ has been reported to induce filaggrin gene expression, which is related to NMF production and induces the gene expression of VEGF (an angiogenesis factor). ${ }^{37,38}$ Moreover, it has been reported that $\mathrm{CO}_{2}$-enriched water induces VEGF expression. ${ }^{17}$ We speculated that $\mathrm{CO}_{2}$ not only improves dermal microcirculation through angiogenesis but also changes the amount of NMF in epidermis via transient hypoxia. We characterized $\mathrm{CO}_{2}$-induced changes in facial skin properties in the present study. However, it is necessary to conduct further investigations to confirm the dose dependency and optimal dosage of efficacy of $\mathrm{CO}_{2}$ in transient or long-term usage and to clarify the molecular mechanism of the effects on skin physiology related to moisturizing, desquamation, and the microenvironment, such as intercellular or intracellular $\mathrm{pH}$ and NMF synthesis.

\section{Conclusion}

We assessed the effect of continuous external application of high-concentration $\mathrm{CO}_{2}$ on functional changes and appearance in facial skin using a formulation that could be applied to localized sites. The results indicated that $\mathrm{CO}_{2}$ prevents skin impairment, such as decreased skin barrier and moisturizing functions and surface roughening, which occur during the dry winter months. This is the first study characterizing changes in facial skin properties induced by $\mathrm{CO}_{2}$ treatment. These findings can be utilized to develop novel skin care methods for skin diseases or symptoms such as dry skin and rough skin and to propose medical treatment for abnormalities in skin barrier and keratinization functions, such as winter xerosis.

\section{Acknowledgments}

We would like to thank Yuuka Kobayashi-Takahota and Masaru Hosokawa for providing the test samples at Skin Care Laboratories, Kao Corporation. This study was entirely funded by Kao Corporation, Tokyo, Japan.

\section{Author contributions}

All authors contributed to data analysis, drafting and revising the article, gave final approval of the version to be published, and agree to be accountable for all aspects of the work.

\section{Disclosure}

All authors are employees of Kao Corporation, which investigates chemical materials and cosmetic products. The authors report no other conflicts of interest in this work.

\section{References}

1. Elias PM. Defensive functions of the stratum corneum: integrative aspects. Skin Barrier. Elias PM, Feingold KR, editors. New York: Taylor and Francis; 2006:535-552.

2. Feingold KR. The outer frontier: the importance of lipid metabolism in the skin. J Lipid Res. 2009;50(Suppl):S417-S422.

3. Rawlings AV, Harding CR. Moisturization and skin barrier function. Dermatol Ther. 2004;17(Suppl 1):43-48. 
4. Black D, Del Pozo A, Lagarde JM, Gall Y. Seasonal variability in the biophysical properties of stratum corneum from different anatomical sites. Skin Res Technol. 2000;6(2):70-76.

5. Qiu H, Long X, Ye JC, et al. Influence of season on some skin properties: winter vs. summer, as experienced by 354 Shanghaiese women of various ages. Int J Cosmet Sci. 2011;33(4):377-383.

6. Kezic S. Skin barrier in atopic dermatitis. Front Biosci. 2014;19(3): 542-556.

7. Rawlings AV, Matts PJ. Stratum corneum moisturization at the molecular level: an update in relation to the dry skin cycle. J Invest Dermatol. 2005;124(6):1099-1110.

8. Nishimura N, Sugenoya J, Matsumoto T, et al. Effects of repeated carbon dioxide-rich water bathing on core temperature, cutaneous blood flow and thermal sensation. Eur J Appl Physiol. 2002;87(4-5):337-342.

9. Sato M, Kanikowska D, Iwase S, et al. Effects of immersion in water containing high concentrations of $\mathrm{CO}_{2}\left(\mathrm{CO}_{2}\right.$-water $)$ at thermoneutral on thermoregulation and heart rate variability in humans. Int J Biometeorol. 2009;53(1):25-30.

10. Savin E, Bailliart O, Bonnin P, et al. Vasomotor effects of transcutaneous $\mathrm{CO}_{2}$ in stage II peripheral occlusive arterial disease. Angiology. 1995;46(9):785-791.

11. Schnizer W, Erdl R, Schöps P, Seichert N. The effects of external $\mathrm{CO}_{2}$ application on human skin microcirculation investigated by laser Doppler flowmetry. Int J Microcirc Clin Exp. 1985;4(4):343-350.

12. Ito T, Moore JI, Koss MC. Topical application of $\mathrm{CO}_{2}$ increases skin blood flow. J Invest Dermatol. 1989;93(2):259-262.

13. Fabry R, Monnet P, Schmidt J, et al. Clinical and microcirculatory effects of transcutaneous $\mathrm{CO}_{2}$ therapy in intermittent claudication. Randomized double-blind clinical trial with a parallel design. Vasa. 2009;38(3):213-224.

14. Schmidt J, Monnet P, Normand B, Fabry R. Microcirculatory and clinical effects of serial percutaneous application of carbon dioxide in primary and secondary Raynaud's phenomenon. Vasa. 2005;34(2):93-100.

15. Nemeth B, Kiss I, Jencsik T, et al. Angiotensin-converting enzyme inhibition improves the effectiveness of transcutaneous carbon dioxide treatment. In Vivo. 2017;31(3):425-428.

16. Minamiyama M, Yamamoto A. Direct evidence of the vasodilator action of carbon dioxide on subcutaneous microvasculature in rats by use of intra-vital video-microscopy. J Biorheology. 2010;24(1):42-46.

17. Irie $H$, Tatsumi $T$, Takamiya $M$, et al. Carbon dioxide-rich water bathing enhances collateral blood flow in ischemic hindlimb via mobilization of endothelial progenitor cells and activation of NO-cGMP system. Circulation. 2005;111(12):1523-1529.

18. Sakai Y, Miwa M, Oe K, et al. A novel system for transcutaneous application of carbon dioxide causing an "artificial Bohr effect" in the human body. PLoS One. 2011;6(9):e24137.

19. Bock M, Schürer NY, Schwanitz HJ. Effects of $\mathrm{CO}_{2}$-enriched water on barrier recovery. Arch Dermatol Res. 2004;296(4):163-168.

20. Pagourelias ED, Zorou PG, Tsaligopoulos M, Athyros VG, Karagiannis A, Efthimiadis GK. Carbon dioxide balneotherapy and cardiovascular disease. Int J Biometeorol. 2011;55(5):657-663.

21. Komoto Y, Kohmoto T, Sunakawa M, Eguchi Y, Yorozu H, Kubo Y. Dermal and subcutaneous tissue perfusion with a $\mathrm{CO}_{2}$-bathing. Phys Med Rehab Kuror. 1986;38(2):103-112.
22. Eguchi Y. Functions of carbonated bath tablets. Cosmetics \& Toiletries in Bath Products Documentary. Carol Stream, IL: Allured Publishing Corp; 1986;101:69-78.

23. Brandi C, D'Aniello C, Grimaldi L, et al. Carbon dioxide therapy in the treatment of localized adiposities: clinical study and histopathological correlations. Aesthetic Plast Surg. 2001;25(3):170-174.

24. Conti A, Rogers J, Verdejo P, Harding CR, Rawlings AV. Seasonal influences on stratum corneum ceramide 1 fatty acids and the influence of topical essential fatty acids. Int J Cosmet Sci. 1996;18(1):1-12.

25. Rogers J, Harding C, Mayo A, Banks J, Rawlings A. Stratum corneum lipids: the effect of ageing and the seasons. Arch Dermatol Res. 1996;288(12):765-770.

26. De Paepe K, Lagarde JM, Gall Y, Roseeuw D, Rogiers V. Microrelief of the skin using a light transmission method. Arch Dermatol Res. 2000;292(10):500-510.

27. Choi JW, Kwon SH, Huh CH, Park KC, Youn SW. The influences of skin visco-elasticity, hydration level and aging on the formation of wrinkles: a comprehensive and objective approach. Skin Res Technol. 2013;19(1):e349-e355.

28. Sato J, Denda M, Nakanishi J, Koyama J. Dry condition affects desquamation of stratum corneum in vivo. J Dermatol Sci. 1998;18(3) 163-169.

29. Egawa M, Oguri M, Kuwahara T, Takahashi M. Effect of exposure of human skin to a dry environment. Skin Res Technol. 2002;8(4) 212-218.

30. Yoshida-Amano Y, Nomura T, Sugiyama Y, Iwata K, Higaki Y, Tanahashi M. Dry skin conditions are related to the recovery rate of skin temperature after cold stress rather than to blood flow. Int $J$ Dermatol. 2017;56(2):176-183.

31. Nomura T, Yoshida-Amano Y, Yoshida K, et al. Relationships between transepidermal water loss, cutaneous microcirculatory function and autonomic nervous activity. Int J Cosmet Sci. 2017;39(3):275-283.

32. Angelova-Fischer I, Wuthe D, Zillikens D, Kahle B. Noninvasive bioengineering assessment of the skin barrier function in patients with chronic venous insufficiency. Br J Dermatol. 2010;162(5):1071-1075.

33. Eberlein-König B, Schäfer T, Huss-Marp J, et al. Skin surface pH, stratum corneum hydration, trans-epidermal water loss and skin roughness related to atopic eczema and skin dryness in a population of primary school children. Acta Derm Venereol. 2000;80(3):188-191.

34. Ali SM, Yosipovitch G. Skin pH: from basic science to basic skin care. Acta Derm Venereol. 2013;93(3):261-267.

35. Choi EH, Man MQ, Xu P, et al. Stratum corneum acidification is impaired in moderately aged human and murine skin. J Invest Dermatol. 2007;127(12):2847-2856

36. Lambers H, Piessens S, Bloem A, Pronk H, Finkel P. Natural skin surface $\mathrm{pH}$ is on average below 5, which is beneficial for its resident flora. Int J Cosmet Sci. 2006;28(5):359-370.

37. Wong WJ, Richardson T, Seykora JT, Cotsarelis G, Simon MC. Hypoxiainducible factors regulate filaggrin expression and epidermal barrier function. J Invest Dermatol. 2015;135(2):454-461.

38. Rezvani HR, Ali N, Serrano-Sanchez M, et al. Loss of epidermal hypoxia-inducible factor- $1 \alpha$ accelerates epidermal aging and affects re-epithelialization in human and mouse. J Cell Sci. 2011;124(Pt 24):4172-4183.
Clinical, Cosmetic and Investigational Dermatology

\section{Publish your work in this journal}

Clinical, Cosmetic and Investigational Dermatology is an international, peer-reviewed, open access, online journal that focuses on the latest clinical and experimental research in all aspects of skin disease and cosmetic interventions. This journal is included on PubMed. The manuscript management system is completely online
Dovepress

and includes a very quick and fair peer-review system, which is all easy to use. Visit http://www.dovepress.com/testimonials.php to read real quotes from published authors 